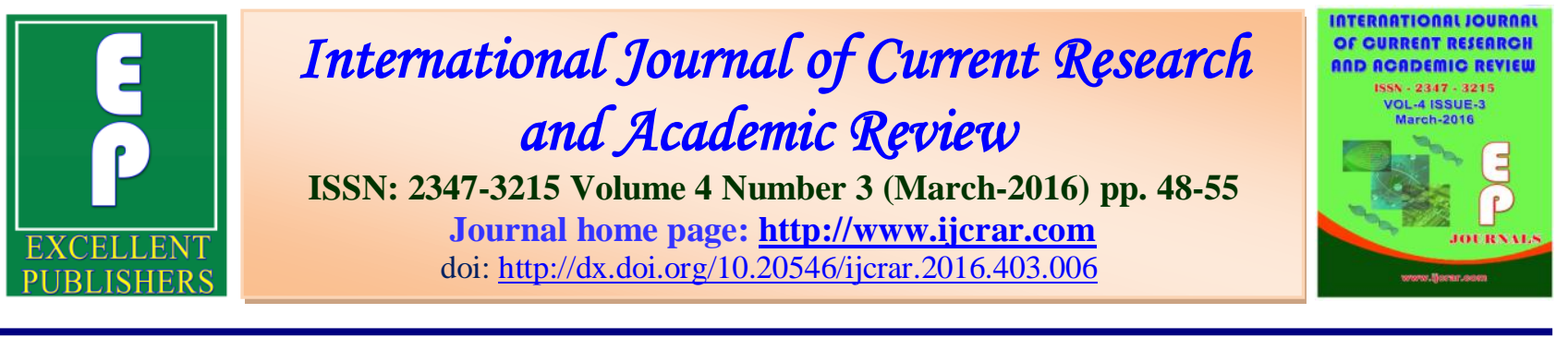

\title{
Breeding and Life Cycle of Fresh Water Ornamnetal Shrimp-Indian White Banded Shrimp, Caridina cf. babaulti Var. Indian White Banded
}

\author{
Ganesh Ariyanathan* and J. Sesh Serebiah
}

Jehovah Shamma Centre for Marine and Wildlife Research, Mudiveeranpattinam, Ramanathapuram Dt-623513, Tamil Nadu, India

*Corresponding author

\begin{tabular}{|c|c|}
\hline KEYWORDS & $A B S T R A C T$ \\
\hline $\begin{array}{l}\text { Caridina } \\
\text { cf. babaulti, } \\
\text { Life cycle of fresh } \\
\text { water, Ornamnetal } \\
\text { shrimp, } \\
\text { Slime production, } \\
\text { DNAse and } \\
\text { Haemagglutination. }\end{array}$ & $\begin{array}{l}\text { There is an evergreen demand for ornamental shrimps in the scope of planted } \\
\text { aquarium or in dedicated aquaria this exponential growth in the demand needs } \\
\text { a steady supply of stocks so the main objective of this research is to develop a } \\
\text { standard hatchery technology for fresh water ornamental shrimps. An } \\
\text { endemic species Indian White banded Shrimp, Caridina cf. babaulti was } \\
\text { selected, as the documented information about the species is scare. Thus, this } \\
\text { study was conducted to gather some information on its breeding behavior and } \\
\text { life cycle until first maturity in laboratory condition.10 pairs of Indian White } \\
\text { banded Shrimp, Caridina cf. babaulti are kept in confined system separately. } \\
\text { The tanks are populated with common aquatic plants (Java fern Microsorum } \\
\text { pteropus, Amazon sword Echinodorus bleherae, Anubias nana, Cryptocoryne } \\
\text { sp., Rotala indica and mosses (java moss Taxiphyllum barbieri, Christmas } \\
\text { moss Vesicularia montagnei) and regulated with periodic photoperiods and } \\
\text { Co2 supply. With carefully monitored water quality parameters, the selected } \\
\text { species was bred in confined system. It was observed that water temperature } \\
\text { is one of the parameter that played a crucial role in influencing the spawning } \\
\text { behavior of the species. Larvae assume a benthic lifestyle after hatching, i.e. } \\
\text { they are miniature versions of the adults. There is no planktonic larval stage. } \\
\text { The hatchlings of this shrimp are extremely small and grow slowly. }\end{array}$ \\
\hline
\end{tabular}

\section{Introduction}

Indian White banded Shrimp, Caridina $c f$. babaulti is an indigenous species. This species comes from pond, river, agricultural canals, mountain streams and reservoirs of its indigenous area.
Many freshwater shrimp from the family Atyidae have been gaining popularity in the aquarium industry over the past years (Heerbrandt and Lin, 2006). Caridina $c f$. babaulti is one of these atyids. The subdued coloration looks contrast to green aquatic 
plant or against dark colored background. Not only this shrimp enriched the look of the freshwater tank, it is also excellent maintenance crews in a cleaning the aquatic plants compared to other shrimp. Currently the demand for this species in the industry is met by wild caught.

In Taiwan, there are 15 species of atyid from 3 genera which include Atyopsis, Caridina and Neocaridina (Hung et al., 1993; Shih and Cai, 2007). Similar to palaemonid shrimps, atyidae demonstrated three types of larval development, normal, abbreviated and completely suppressed (Shokita, 1981; Shy, 1994). Most of these atyids undergoes the normal type of larval development and produce relatively smallsized eggs with long planktonic phase. As for abbreviated type, larval of planktonic phase only takes few days. However, for the completely suppressed type, eggs were relatively large-sized without planktonic phase since the larvae hatched in benthic form.

The Indian ornamental fish sector is a small but vibrant segment, with potential for tremendous growth and large-scale gainful employment generation. At present the ornamental fish export from India is dominated by the wild caught species, which cater to a small portion of the global market. India's contribution to global ornamental fish trade is negligible. The country is bestowed with climatic conditions ideally conducive for growth, maturation and breeding of many exotic as well as indigenous ornamental fishes. Shrimp are decapods or 10 limbed crustaceans along with crayfish, cherax crabs and others. Historically only crayfish were kept, in the last 10-15 years shrimp and other crustaceans have become increasingly popular in home aquaria. The scope of shrimp keeping in planted aquarium or in dedicated aquaria is increasing among the hobbyist. This exponential growth in the demand needs a steady supply of stocks so the main objectives of this research are to develop a standard hatchery technology for fresh water ornamental shrimps and producing desirable strains with the help of selective breeding and interbreeding.

\section{Materials and Methods}

Brood stocks of each species are maintained in glass tank (40 x $20 \times 25)$ supported with bio-chemical filter systems. Plants growth is aided with Compact Florescent lamp at a ratio of 1watt per 5 liters, Mopani driftwood and suitable soil substrates.

\section{Shrimp Species}

\section{Indian White banded Shrimp}

Indian White Banded Shrimp (Caridina $c f$. babaulti var. Indian white banded) are another of the variations of Babulti shrimp in the hobby. Like other Babaulti shrimp, they are freshwater and originally from India. Indian White Banded Shrimp are rarer than some of the other Babulti shrimp in the hobby such as Green Babaulti. Both males and females are light red in color with white banded on the body. Indian White banded Shrimps are excellent algae eaters and almost better substrate sifters. Where these shrimp are present in greater numbers there will not be any problems with different kinds of algae covering your substrate. These little guys will take care of it. They are especially effective on a sandy substrate, where they clean the sand grain by grain.

Shrimp are much less tolerant of poor water conditions than most fish. Ammonia, nitrites and nitrates will eventually kill the shrimp, even if only a small amount of uneaten food remains in the aquarium. For biological 
filtration, elevated air-driven sponge filters with a medium to slow air flow are used. As for substrate, fine-grain, gravel and also white silica sand were used. For some species, such as the hardy red cherry shrimp, coral sand or gravel, as they enjoy a more alkaline environment. Slower-growing plant species, such as Java moss and Java fern, work pretty well in a shrimp aquarium. Use of fast-growing plants in a shrimp aquarium is probably a mistake because they tend to suck up needed nutrients. This suggestion had been made on the Petshrimp forum (www.petshrimp.com), and it was probably the reason cherry shrimp colony hadn't been as prolific with some hobbyist. When the fast-growing plants were removed and went back to Java moss, shrimps did much better and hobbyists started seeing a lot more baby shrimp in the aquarium.

\section{Water Parameters}

Some of the shrimp species prefer soft, acidic water with temperatures between $24^{0} \mathrm{C}-28^{\circ} \mathrm{C}$; others prefer a more alkaline $\mathrm{pH}$ and harder water. For each shrimp species the water parameters are different. Shrimp need clean water, so 30 percent of water was changed at least once every two weeks, and its better if changes are performed weekly. Aeration was provided throughout the study period.

Shrimp are especially sensitive to chlorine or chloramines in city water supplies, so it's important to use a dechlorinator or ammonia neutralizer to remove these chemicals. Quality products that neutralize ammonia are important. If chlorine and/or ammonia aren't eliminated, the shrimp will die. Invertebrates-especially shrimp-are very sensitive to copper. Never treat an aquarium with any copper-containing product if the aquarium houses shrimp. It has been suggested that there might even be too much copper released from home water pipes when mixing hot water to equalize the temperature of replacement water.

Copper is not the only thing that can harm shrimp. Many of the anti-parasite products on the market will have devastating results on shrimp, so this is just another good reason to have a shrimp-only aquarium. If fish are to be kept with the shrimp, put the fish in a quarantine aquarium first for several weeks before introducing them to the display aquarium so that any disease that would require anti-parasite medications can be dealt with there.

The kits or apparatus used were; DO meter (dissolved oxygen and temperature) and API aquarium freshwater test kit $(\mathrm{pH}$, ammonia, nitrite). Measurements were taken twice a week.

\section{Feeding Shrimp}

Caridina $c f$. babaulti are not picky eaters and will eat dead plant matter along with algae, algae wafers and other omnivorous foods. Healthy shrimps skitter all over an aquarium, constantly searching for food. They seem to never hold still and are always moving about. When food is dropped into the aquarium, they soon sense it and scurry to the front of the aquarium to eat. Shrimp will drop their shell (molt) every once in a while. It takes a day or two after the molt for their new shell to harden, and they will usually try to stay hidden from predators during this time. They are extremely vulnerable during this process, which is another good reason to keep fish out of their aquarium.

Shrimp will do fine on basic fish food pellet or flake. Feed only an amount that can be eaten in a few minutes. Shrimp will also find their own food when aquatic plants like 
Java moss and Java fern are growing in their aquarium. Many shrimpers advocate putting waterlogged dead oak leaves or other leaf varieties in the aquarium as a source of food for the shrimp. Make sure that the leaves have been soaked for several weeks before adding them to the aquarium to ensure that most of the tannins have leached out. The leaves slowly decay, and the shrimp seem to feed on both the leaves and the other organisms that break down the leaves.

\section{Shelter}

No shelter was provided for the shrimps because the aquarium tanks were exclusively maintained for shrimp species alone so there was no risk of predation during molting period.

\section{Brood Stock}

The females are distinguished from the males by their larger size. About 10 females and 10 males used were with average total length of $2.5 \pm 0.5 \mathrm{~cm}$ and placed into two separated conditioning tanks. Conditioning process takes about two weeks. Only females with saddle and healthy males were used.

\section{Breeding}

These shrimps are bit slow to breed and also in growth, but will reproduce when kept in prime conditions and tend to breed more when kept in hard water. Ten pairs of matured male and female shrimps were placed in breeding tank. Observation was carried until female shrimp become ovigerous.

\section{Larvae}

Number of larvae produced by each female was counted and recorded. Larvae produced from the earlier experiment were placed and conditioned in tanks for a week. After a week, only healthy larvae were used for the next experiment.

\section{Life Cycle}

Indian White Banded Shrimp have a lifespan of about 1-2 years and max out between 0.5 and 1.5 inches in size. They are considered relatively easy to maintain and make a colorful and interesting addition to any aquarium. Thirty larvae (one week old) were placed in tank. Observation was carried out until all the larvae reached first maturity. Life cycle of Caridina $c f$. babaulti was presented into illustration form. Total length (TL) of Caridina cf. babaulti was measured from rostral tip to posteromedian margin of the telson, excluding posterior setae following Yang and Ko (2003). Larvae and eggs were observed and measured using ocular micrometer placed in the microscope eyepiece of Leica DM750, compound microscope with scale bar. Photographs were taken using Sony H50 digital camera. Ranges of water quality parameters observed throughout this study were recorded.

\section{Results and Discussion}

Caridina $c f$. babaulti reached first maturity at around 75 days old with TL $2.3 \pm 0.2 \mathrm{~cm}$. Upon reaching maturity, the presence of visible ovaries can be seen through the cephalothorax region of the females. Appendix masculina on the second pleopod were observed in males. Mating process usually take place 1-3 day(s) after the introduction of male and female into the same tank. Female molted prior to mating.

Both molting and mating occurred rapidly in less than $10 \mathrm{sec}$. During mating process male and female of Caridina $c f$. babaulti will be facing each other and sperm were 
deposited into the genital opening of female Caridina $\quad c f$. babaulti using its appendix masculina. The eggs were fertilized when it passed through the sperm on the way to the brood pouch. The pouch was formed by pleopods and overhanging of pleura of the female. A day after mating, female was observed to carry fertilized eggs. The eggs were incubated in the brood pouch until hatch.

Table.1 Ranges of Water Quality Parameters Measured During the Study Period

\begin{tabular}{|l|c|}
\hline \multicolumn{1}{|c|}{ Parameters } & Range \\
\hline Dissolved Oxygen $\left(\mathrm{mg} \mathrm{L}^{-1}\right)$ & $>4$ \\
\hline Temperature ${ }^{0} \mathrm{C}$ & $24-28$ \\
\hline $\mathrm{pH}$ & $6.8-7.8$ \\
\hline Ammonia $\left(\mathrm{mg} \mathrm{L}^{-1}\right)$ & $<0.1$ \\
\hline Nitrite $\left(\mathrm{mg} \mathrm{L}^{-1}\right)$ & $<0.1$ \\
\hline Hardness & Moderately Hard \\
\hline
\end{tabular}

Table.2 Fecundity by Length for Caridina cf. babaulti

\begin{tabular}{|c|c|c|}
\hline Sample & Total length (cm) & Fecundity \\
\hline 1 & 2.7 & 45 \\
\hline 2 & 2.5 & 43 \\
\hline 3 & 2.6 & 52 \\
\hline 4 & 2.5 & 55 \\
\hline 5 & 2.6 & 45 \\
\hline 6 & 2.7 & 43 \\
\hline 7 & 2.4 & 42 \\
\hline 8 & 2.5 & 56 \\
\hline 9 & 2.7 & 49 \\
\hline 10 & 2.6 & 42 \\
\hline
\end{tabular}

Fig.1 Indian White Banded Shrimp

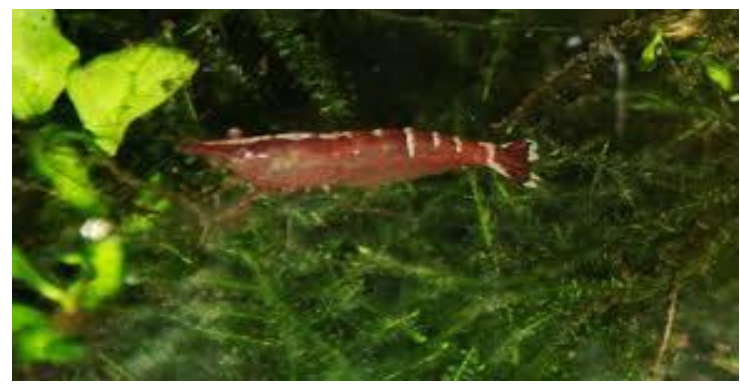


Fig.2 Matured Female (Indian White Banded Shrimp) with Fertilized Eggs

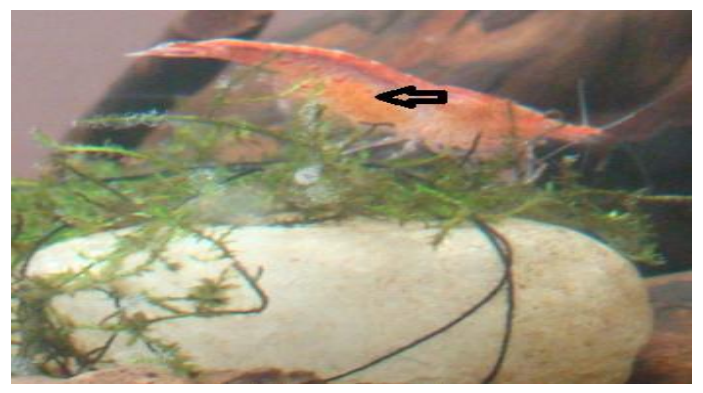

Fig.3 3 Days Old Larvae of Indian White Banded Shrimp

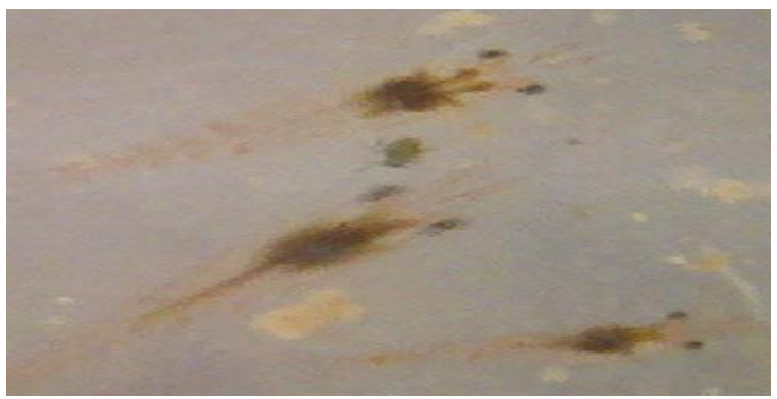

Fig.4 Life cycle of caridina cf. Babaulti

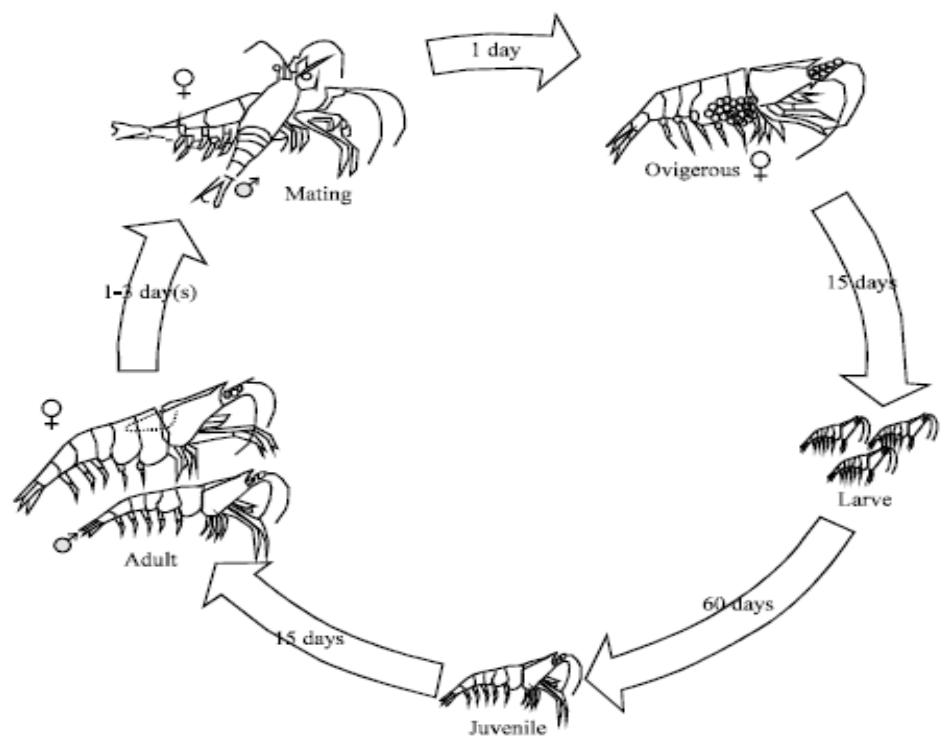

Fertilized eggs were oval in shape, vary from greenish to yellowish in color. The egg size was comparatively large, with an average length $1.19 \mathrm{~mm}$. Thin ribbon-like filament binds the eggs in grape-like bunches and attached it to the female's pleopod. The membrane can hardly be distinguished since it is thin, transparent and lying close to the surface. 
In this study, Caridina $c f$. babaulti was found to be able to reached first maturity as early as 75 days old, which is similar to those reported by Demas (2007). Female molted prior to mating, possibly induced by the released of certain chemical substance into the surrounding water. Somehow, before or during molting, the release of this substance allows the male to detect gravid female in the water column. This signaled the male that female is ready to spawn.

Newly hatched larvae of Caridina $c f$. babaulti look like the miniature version of adult similar to that observed by Yang and Ko (2003). Morphological differences were only observed when $N$. d. sinensis reached maturity with the appearance of endopod and appendix masculine in males, which is similar to the report by Englund and Cai (1999). Caridina $c f$. babaulti lacked of planktonic larval stage, therefore, it is a completely suppressed type based on the type categorized by Lai and Shy (2009). Numbers of egg produced per female of freshwater shrimp is depending on the size of the female itself. Smaller females produced fewer eggs compared to larger females (Ketse, 2006).

Female Caridina $c f$. babaulti was observed to incubate and fan their eggs in the brood pouch. According to Adiyodi and Adiyodi (1994) this kind of parental care will results in higher survival rate of larvae produced. Similar to those reported by Schram (1986), Caridina cf. babaulti eggs were incubated in brood pouch until hatching.

\section{Conclusion}

Caridina $c f$. babaulti var. Indian white banded can successfully breed in laboratory conditions using a simple experimental setup. This shrimp is able to reach first sexual maturity earliest at 75 days old. It reproduces throughout the year. The findings of this study can be used as a guideline for culturist interested in the mass production of this ornamental shrimp for the aquarium industry.

\section{Acknowledgment}

I would like to thank Dr. J. Sesh Serebiah, M.Sc., Ph.D, Principal Scientist, Jehovah shamma Centre for Marine and Wildlife Research, Mudiveeranpattinam, Ramanathapuram Dt-623513, (Contact: 9443608847) for providing valuable support for this research.

\section{References}

Adiyodi, K.G., Adiyodi, R.G. 1994. Reproductive Biology of Invertebrates, Volume 6, Part B, Asexual Propagation and Reproductive Strategies. John Wiley, USA, ISBN: 978-0-471-94119-4.

Cai, Y. 1996. A revision of the genus Neocaridina (Crustacea: Decapoda: Atyidae). Acta Zootaxon. Sin., 21: 129-160.

Demas, P. 2007. Red Cherry Shrimp. Trop. Fish Hobbyist, 56: 90-92.

Englund, R.A., Cai, Y. 1999. The occurrence and decription of Neocaridina denticulata sinensis (Kemp, 1918) (Crustacea: Decapoda: Atyidae), a new introduction to the Hawaiian Islands. Bishop Museum Occasional Papers No. 58, pp. 58-65. http://hbs. bishopmuseum.org/pdf/englund\&cai 99.pdf.

Nur, F.A.H., Christianus, A. 2013. Breeding and Life Cycle of Neocaridina denticulata sinensis (Kemp, 1918). Asian J. Ani. Veterinary Adv., 8: 108-115. 
Heerbrandt, T.C., Lin, J. 2006. Larviculture of red front shrimp, Caridina gracilirostris (Atyidae, Decapoda). J. World Aquacult. Soc., 37: 186190.

Hung, M.S., Chan, T.Y., Yu, H.P. 1993. Atyid shrimps (Decapoda: Caridea) of Taiwan, with descriptions of three new species. $J$. Crustacean Biol., 13: 481-503.

Ketse, N. 2006. The effects of selected reference toxicants on embryonic development of the freshwater shrimp Caridina nilotica(Decapoda: Atyidae). M.Sc. Thesis, Institute for Water Research, Rhodes University, Grahamstown, South Africa.

Lai, H.T., Shy, J.Y. 2009. The Larval Metamorphosis of Caridina pseudodenticulata (Crustacea;

Decapoda; Atyidae) rearing in the laboratory, with a discussion of larval metamorphosis types. Raffles Bull. Zool., 20: 97-109.

Schram, F.R. 1986. Crustacea. Oxford University Press, Oxford.
Shih, H.T., Cai, Y. 2007. Two new species of the land-locked freshwater shrimps genus Neocaridina Kubo, 1938 (Decapoda: Caridea: Atyidae), from Taiwan, with notes on speciation on the island. Zool. Stud., 46: 680-694.

Shokita, S. 1981. Life-history of the family Atyidae (Decapoda, Caridea). Aquabiol., 12: 15-23.

Shy, J.Y. 1994. Taxonomy, distribution and ontogeny of freshwater shrimps and crabs in Taiwan. Ph.D. Thesis, National Taiwan Ocean University, Keelung.

Yang, H.J., Ko, H.S. 2003. Larval development of Neocaridina denticulate sinensis (Decapoda: Caridea: Atyidae) reared in the laboratory. Korean J. Syst. Zool., 19: 49-54.

https://www.bobstropicalplants.com/sho p/en/shrimp/459-indian-whitebandedshrimp.html (25/02/2016)

\section{How to cite this article:}

Ganesh Ariyanathan and J. Sesh Serebiah. 2016. Breeding and Life Cycle of Fresh Water Ornamnetal Shrimp-Indian White Banded Shrimp, Caridina cf. babaulti Var. Indian White Banded. Int.J.Curr.Res.Aca.Rev.4(3): xx-xx. doi: http://dx.doi.org/10.20546/ijcrar.2016.403.006 